\title{
Pediatric Urethral Strictures and Management Strategies; An Evolving and Learning Experience
}

\author{
(1) Mir Fahiem-ul-Hassan, (1) Vinay Jadhav, (1) Narendrababu Munianjanappa, (1) Murali Saroja \\ Indira Gandhi Institute of Child Health, Banglore, India
}

\begin{abstract}
Aim: Most of the surgical strategies for pediatric urethral strictures (PUS) are derived from adult experiences. Owing to this, we carried out this study to assess the management strategies for PUS in our institute.

Materials and Methods: This prospective study included 28 patients with PUS. Preoperatively, patients were assessed clinically and were subjected to voiding cystourethrography (VCUG) and pre-procedure cystoscopy. Intraoperatively, urethroscopy, VCUG and retrograde urethrography were used to evaluate the length of the stricture. Urethral dilatation (UD), direct visualization and internal urethrotomy (DVIU), excision and primary anastomosis (EPA) with or without pubectomy and dorsal onlay urethroplasty (DOU) were the procedures instituted to treat the strictures. After the procedure, a silicone catheter was left in situ for 1-2 weeks in cases of DU or DVIU and 4-6 weeks in cases of EPA or DOU. Postoperatively, patients were assessed in terms of their symptoms and for VCUG/cystoscopic evidence of reestablishment of urethral continuity. There was an average follow-up period of 1.9 years.

Results: Three patients were successfully treated with single session UD and another three with multiple sessions. Two UD patients required EPA. DVIU was performed in four patients. This procedure failed in one and so required EPA. EPA was carried out in fourteen patients with two requiring redo-EPA. Graft onlay urethroplasty was performed in five patients with satisfactory results.

Conclusion: The procedure to address a stricture should be tailored to the individual urethral anatomy, stricture length and the surgeons' experience. For smaller and partially obstructing strictures, DVIU and DU can be tried but these procedures seem to be less effective than EPA, with high rates of secondary procedures. However, if not accompanied by complete excision of fibrosed spongiosum, EPA may have to be repeated. For longer bulbar strictures, substitution urethroplasties are viable alternatives.
\end{abstract}

Keywords: Pediatric urethral strictures, urethral dilatation, direct visualisation and internal urethrotomy, excision and primary anastomosis

\section{Introduction}

Pediatric urethral injuries differ remarkably from adult urethral injuries. The pediatric urethra is short, immobile and inadequately protected by an immature pelvis thus making it susceptible to injuries (1). Posterior urethral injuries are more frequent than the anterior urethral injuries owing to the intraabdominal location of the bladder and the cranial placement of the prepubescent prostate (2). It has been observed that in pediatric pelvic fractures, 69\% suffer prostatic urethral displacement compared to $42 \%$ in adults (3). Anterior urethra is less commonly involved with the bulbar urethra representing the most common area of anterior urethral injury in boys (1). Apart from this, there are instances of congenital urethral strictures which, though rare, are thought to be more frequent than suggested by 
the literature (4). The consequences of pediatric urethral strictures (PUS) may be devastating and appropriate intervention is necessary for a successful outcome. Being rare, consensus over the best surgical approach for repair is lacking (5). In addition, most of the experience with these surgical approaches is derived from adult series. Owing to this, we conducted this study to assess the management strategies for PUS in our pediatric surgical unit.

\section{Materials and Methods}

This prospective study extended from November 2012 to November 2020 and was carried out with ethical clearance by the Institutional Ethical Committee and the receipt of informed consent from the legal guardians of the patients. Those patients in the pediatric age group operated on for urethral strictures were included in this study but those who did not complete a follow-up were excluded. The study period was 8 years. Preoperatively, all the patients were assessed clinically for symptoms such as dribbling, straining at voiding, retention of urine, dysuria and urinary tract infections. All the patients were subjected to voiding cystourethrography (VCUG) and pre-procedure cystoscopy. Intraoperatively, cysto-urethroscopy, VCUG and retrograde urethrography were carried out to evaluate the length of the stricture.

Urethral dilatation (UD), direct visualization and internal urethrotomy (DVIU), excision and primary anastomosis (EPA) and dorsal onlay urethroplasty (DOU, Barbagli technique) were the procedures performed to treat the strictures.

UD was done by metallic dilators and DVIU was performed by cold knife. EPA was performed via perineal midline incision followed by circumferential mobilization and the excision of fibrosed and scarred tissue. Tension free, epithelium to epithelium anastomosis was carried out after proper spatulation. Inferior pubectomy (pubic bone carving) was performed in patients when there was difficulty in approximating the urethral ends. DOU was also performed via midline perineal incision. After mobilization, the urethra was rotated 180 degrees, a longitudinal urethrotomy was carried out and buccal graft sutured in place.

An appropriate size silicone catheter was left in situ for 1-2 weeks in cases of DU or DVIU and 4-6 weeks in cases of EPA or DOU.

Postoperatively, patients were assessed at regular intervals for symptoms and their radiological investigations were recorded. Success was defined as the resolution of symptoms, successful initiation and completion of voiding with VCUG/cystoscopic evidence of the reestablishment of urethral continuity. The minimum follow-up was for six months and maximum for six years (mean followup: 1.9 years). Long term results with regards to erectile dysfunction are not yet known.

\section{Results}

Over a period of eight years, 28 patients were managed for urethral strictures. The median age of the patients was 6.5 years at the time of repair (range 3 months to 16 years). The most common etiology was trauma (Table I). Posterior urethra was involved more frequently $(n=19$, $67.8 \%)$ than the anterior urethra $(n=9,32.2 \%)$. Symptoms

\begin{tabular}{|c|c|c|}
\hline Etiology & $\begin{array}{l}\text { Number of } \\
\text { patients }\end{array}$ & $\%$ \\
\hline Traumatic & 16 & 57.1 \\
\hline Motor vehicle accidents & 13 & 46.4 \\
\hline Straddle injuries & 3 & 10.7 \\
\hline latrogenic & 7 & 25 \\
\hline Post PUV fulgration & 5 & 17.8 \\
\hline Post-catherisation & 1 & 3.6 \\
\hline Operated anorectal malformation & 1 & 3.6 \\
\hline Idiopathic & 2 & 7.1 \\
\hline Congenital & 3 & 10.7 \\
\hline \multicolumn{3}{|l|}{ Location } \\
\hline Posterior & 19 & 67.8 \\
\hline Anterior & 9 & 32.2 \\
\hline \multicolumn{3}{|l|}{ Symptomatology } \\
\hline Diversion & 15 & 53.5 \\
\hline Poor stream & 10 & 35.7 \\
\hline Straining & 9 & 32.1 \\
\hline Incomplete emptying & 5 & 17.8 \\
\hline Dysuria & 5 & 17.8 \\
\hline Urinary tract infection & 4 & 14.9 \\
\hline \multicolumn{3}{|l|}{ Associations } \\
\hline VUR & 6 & 21.4 \\
\hline ARM & 1 & 3.6 \\
\hline Seminal vesicle cyst & 1 & 3.6 \\
\hline Solitary kidney & 1 & 3.6 \\
\hline Pouch colon & 1 & 3.6 \\
\hline Urethral diverticulum & 1 & 3.6 \\
\hline VUJO & 1 & 3.6 \\
\hline
\end{tabular}


and signs at the time of presentation are provided in Table I. Fifteen patients (53.5\%) were on diversion in the form of suprapubic catheter or temporary vesicostomy when they were admitted to the unit. The associated comorbidities were vesicoureteral reflux, anorectal malformation, seminal vesical cyst, solitary kidney, pouch colon and urethral diverticulum. One patient with urethral diverticulum had a diverticulum in the anterior urethra, stricture in the posterior urethra and pouch colon.

The procedures undertaken were UD $(n=8), \operatorname{DVIU}(n=4)$, excision of the stricture with primary anastomosis $(n=11)$ and DOU ( $n=5)$ (Table II). Single session UD was successful in 3 patients while the other five needed multiple sessions. Two of these patients eventually required EPA (Figure 1). DVIU was performed in four patients and it was unsuccessful in one who then required EPA. EPA were carried out in 14 patients including patients who underwent unsuccessful UD and DVIU. All the patients in the EPA group had posterior urethral strictures. Nine of the EPA-group patients had pelvic distraction injuries with complete disruption of the urethral lumen by a fibrotic tissue (Figure 2). These strictures were not negotiable by Terumo guidewire on urethra-cystoscopy. The initial two EPA patients developed recurrence requiring redo-EPA. These two patients had stricture lengths of $3.5 \mathrm{~cm}$ and $4.0 \mathrm{~cm}$ respectively. Graft onlay (DOU) procedures were done by Barbagli technique (Figure 3). Barbagli technique was performed in bulbar urethral strictures with compromised luminal patency. All of these patients are currently symptom free. Patients were followed up for at least 6 months and up to six years with a mean follow-up period of 1.9 years. The long-term results

with regards to erectile dysfunction are not available to date.

\section{Discussion}

Urethral strictures in pediatric patients, though uncommon, can be very distressing for the patients and their care-givers (5). Urethral trauma leading to strictures is usually sustained by pelvic fractures due to motor vehicle accidents $(6,7)$. The reported incidence of urethral injury in pelvic traumas for boys ranges from $7.4 \%$ to $13.5 \%$

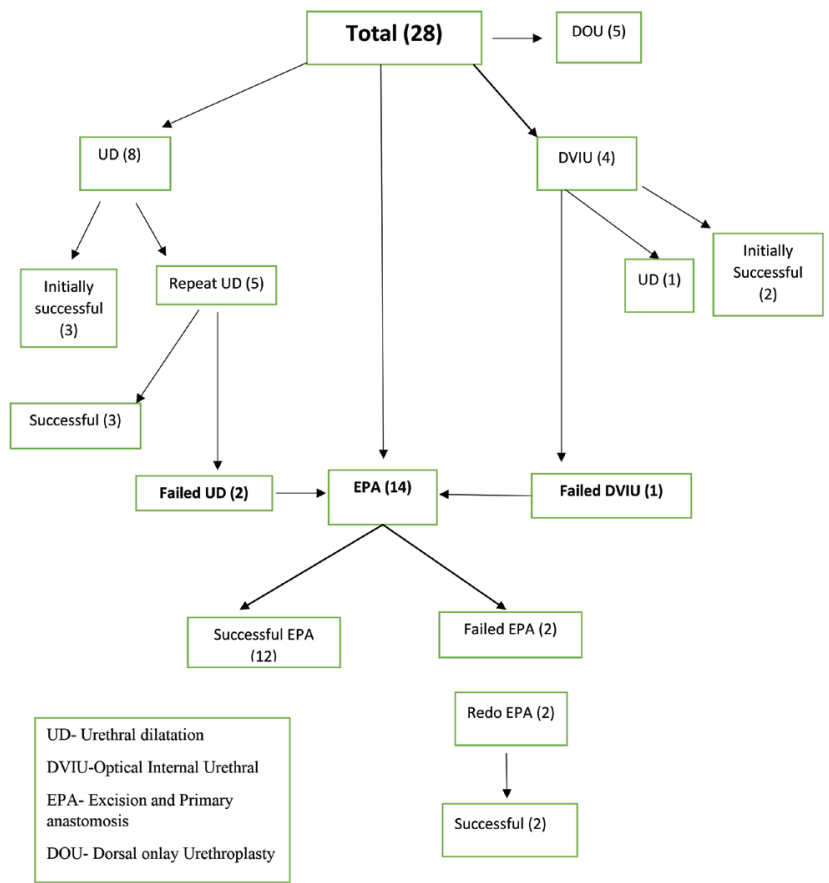

Figure 1. Schematic representation of the current study

Table II. Stricture characteristics and procedures adopted

\begin{tabular}{|c|c|c|c|c|c|}
\hline Procedure & Number of patients & $\begin{array}{l}\text { Region of urethra } \\
\text { involved (n) }\end{array}$ & Etiology (n) & $\begin{array}{l}\text { Mean } \\
\text { stricture length } \\
\text { (n) }\end{array}$ & $\begin{array}{l}\text { Secondary } \\
\text { procedures }\end{array}$ \\
\hline UD & $8(28.6 \%)$ & Ant. (2), Post. (6) & $\begin{array}{l}\text { Congenital (1) } \\
\text { Traumatic (4) } \\
\text { latrogenic (3) }\end{array}$ & $\begin{array}{l}\text { Not mentioned (4) } \\
\text { Point stricture (4) }\end{array}$ & EPA in 2 patients \\
\hline DVIU & $4(14.3 \%)$ & Ant. (2), Post. (2) & $\begin{array}{l}\text { Congenital (1) } \\
\text { Idiopathic (1) } \\
\text { latrogenic (2) }\end{array}$ & $0.4 \mathrm{~cm}$ & EPA in 1 patient \\
\hline EPA & $11(39.3 \%)$ & Post. (11) & $\begin{array}{l}\text { Traumatic (10) } \\
\text { latrogenic (1) }\end{array}$ & $2.2 \mathrm{cms}$ & $\begin{array}{l}\text { Redo EPA in } 2 \\
\text { patients }\end{array}$ \\
\hline $\begin{array}{l}\text { Dorsal onlay } \\
\text { urethroplasty }\end{array}$ & $5(14.3 \%)$ & Ant. (Bulbous) (5) & $\begin{array}{l}\text { Idiopathic (1) } \\
\text { Congenital (1) } \\
\text { latrogenic (1) } \\
\text { Traumatic (2) }\end{array}$ & $3.8 \mathrm{~cm}$ & None \\
\hline
\end{tabular}




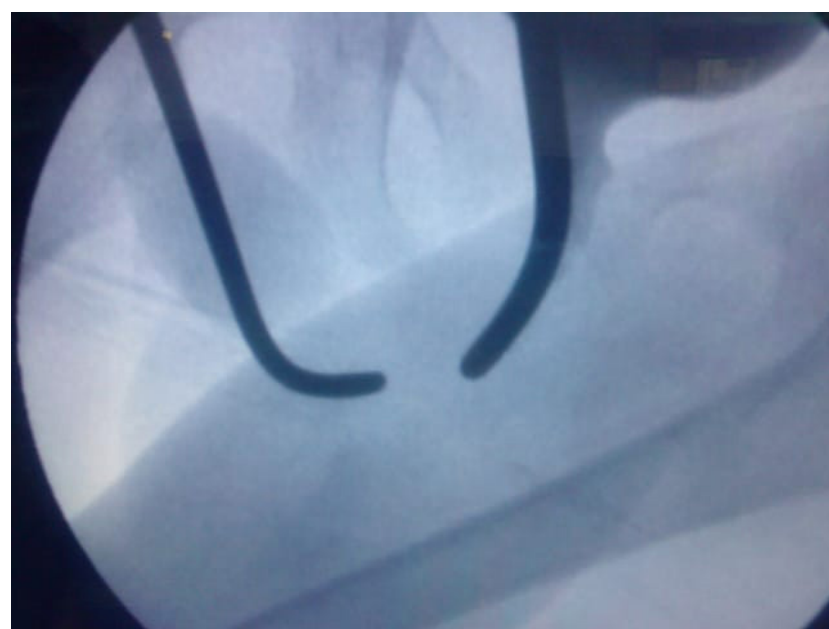

Figure 2. Pelvic distraction injury with complete disruption of urethral lumen

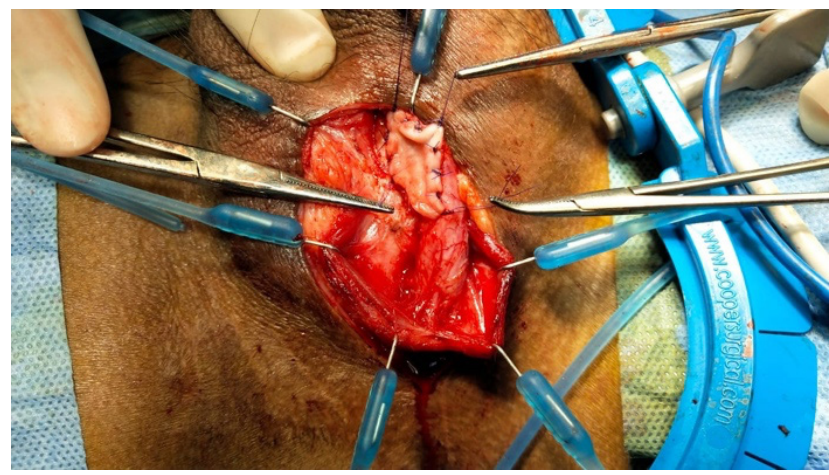

Figure 3. Dorsal onlay urethroplasty

(8). In our study, the most common mode of urethral injuries and subsequent strictures was also due to pelvic trauma acquired by motor vehicle accidents or straddle injuries (Table I). latrogenic trauma was a cause in 7 (25\%) patients with more than half of them $(n=5)$ reporting after posterior urethral valve fulguration. Posterior urethral valve fulguration can lead to stricture formation in $0-25 \%$ of patients (9). This situation is largely preventable if the necessary technical precautions are taken during the procedure. Post-fulguration strictures have usually been reported after the excessive use of diathermy, dry fulgurations in vesicostomies or disproportionate instrumentation in neonates (10). As in our study, the other iatrogenic mechanisms for urethral strictures are urethral catheterization and surgery for anorectal malformation $(5,7)$. Congenital and idiopathic strictures were seen in 3 and 2 patients respectively. Congenital urethral strictures are rare, although the exact prevalence still remains unclear (4). CUS are seen in infancy and early childhood in association with other structural anomalies (11). In a significant number of older patients, there is no obvious cause and such cases are labeled as idiopathic strictures (12). The possible cause of idiopathic strictures is thought to be unrecognized trauma (13).

As in our study, posterior urethra is more frequently involved than anterior urethra. The peculiar anatomy of pediatric urethra makes it more susceptible to trauma and stricture development. In the anterior region, bulbar urethra is the most vulnerable to trauma and subsequent stricture formation due to straddle injury. Due to straddle injury, the bulbar urethra can be compressed against the inferior aspect of the symphysis pubis resulting in trauma and stricture formation (1).

Most posterior urethral strictures are managed by suprapubic cystostomy and delayed repair, though some would favor early primary repair (14). However, an increased incidence of impotence and incontinence has been cited to preclude early primary repair $(1,15)$ and in light of this, our unit follows a protocol of delayed repair. Fifteen (53\%) patients of our PUS were on suprapubic diversion and the rest presented with lower urinary tract symptoms, predominantly with poor stream ( $n=10,35.7 \%)$ and straining $(n=9,32.1 \%)$. It is also worth mentioning two patients who had unusual anomalies. One of them had a congenital urethral stricture with a seminal vesical cyst, and the other one had congenital posterior urethral stricture combined with anterior urethral diverticulum, pouch colon and vesicoureteral reflux. Congenital urethral strictures are known to be associated with other anomalies but associations like pouch colon and seminal vesical cyst are hitherto unknown though hypospadias and prostatic anomalies are very well reported in the literature (16).

Quite a few procedures were applied in the management of patients with urethral strictures. UD was successful in $3(37.5 \%)$ patients with one session. Five (62.5\%) patients received multiple sessions of UD. Of these patients, two patients did not achieve the desired outcomes and so they underwent EPA. UD is the initial management tool for urethral strictures (17). Its success rates are reported to be variable with a stricture recurrence rate of $67-78 \%$ over a 6-year period (18). Nonetheless, combined with DVIU, it definitely has a role to play in the treatment of short strictures especially in congenital and idiopathic strictures in infants (12). DVIU is reported to have similar success rates (50-60\%) as DU (18). In our experience, DVIU was successful in two of the four patients (50\%) after the initial procedure. One patient was symptom free only after a secondary UD. Early recurrence was observed in another patient who underwent EPA later on. DVIU is a quick and 
easy procedure and is primarily useful in short segment $(<2 \mathrm{~cm})$ strictures $(6,18)$. The utility of this technique in the management of recurrent strictures has been questioned but still UD and DVIU, being technically easy and quick, remain the two most frequently performed procedures for smaller urethral strictures (19) despite the better reported results of EPA. EPA involves excision of a urethral stricture along with fibrotic spongiosum (Figure 4 and 5) through a perineal midline or inverted $\mathrm{Y}$-shaped incision. The reported success rates with this technique approach $86 \%$ and thus it may be considered as the optimal treatment of short segment $(2-3 \mathrm{~cm})$ stricture (20). In our study, 14 patients (mean stricture length of $2.2 \mathrm{~cm}$ ) underwent EPA including three patients who had had unsuccessful UD and DVIU. Twelve patients (85.8\%) became symptom-free after the procedure while two patients continued to have obstructive symptoms with persistently raised post-void residual on ultrasonography. On further evaluation and repeat VCUG, both of these patients were shown to have recurrent strictures and were hence re-operated. Both required redoEPA with inferior pubectomy for re-coursing the urethra without causing penile chordee. Following the redo-EPA procedure, both patients had satisfactory results although one had intermittent bouts of stress incontinence. It is worth

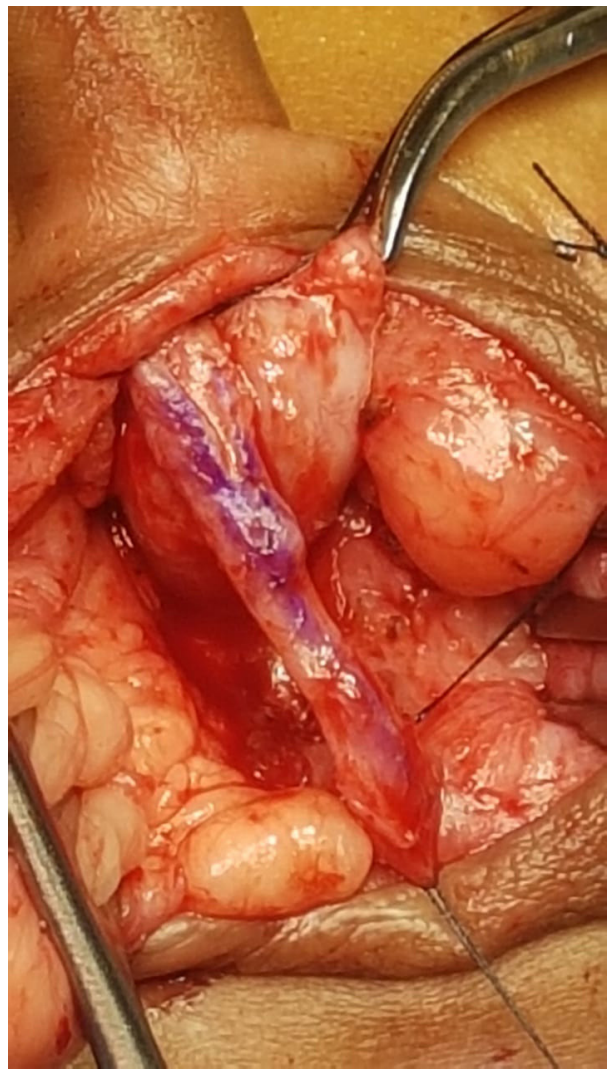

Figure 4. Mobilization of urethra for excision and anastomosis mentioning here that both of these patients had primary repair done during our early experience working with these procedures. Subsequently, with greater experience and from the critical feedback of stalwarts in the field, we realized that partial and incomplete excision of fibrosed spongiosum was responsible for the recurrences, and this was rectified in subsequent procedures. EPA is a technically demanding procedure especially in the pediatric pelvic configuration and it has a steep learning curve $(21,22)$. Yet after the initial two failures, all twelve EPA patients had satisfactory results in terms of symptom improvement and micturition stream on VCUG. Cystoscopy at 6 weeks revealed a patent urethra in all of them (Figure 6). As none of the procedures is an ideal solution for PUS, EPA also comes with its own set of issues. We encountered stress incontinence in two patients and increased frequency in two patients, which were subtle and non-worrying for the patients and thought to be due to some amount of sphincter damage in high posterior urethral strictures.

However, ejaculatory dysfunction, decreased glans sensation, chordee and erectile dysfunction have been reported in the literature as some of the main complications of EPA (20). Sexual complications after EPA are reportedly higher than for buccal urethroplasty patients, although the buccal group usually have much longer strictures (23). Buccal mucosa may be used as ventral or dorsal onlay graft. We performed dorsal onlay procedure in five patients. Three patients received buccal mucosal grafts and one received anterior urethral strip as a dorsal onlay graft. This last patient was also the patient with anterior urethral diverticulum and posterior urethral stricture. Urethral strip from the diverticulum was used as an onlay graft for the

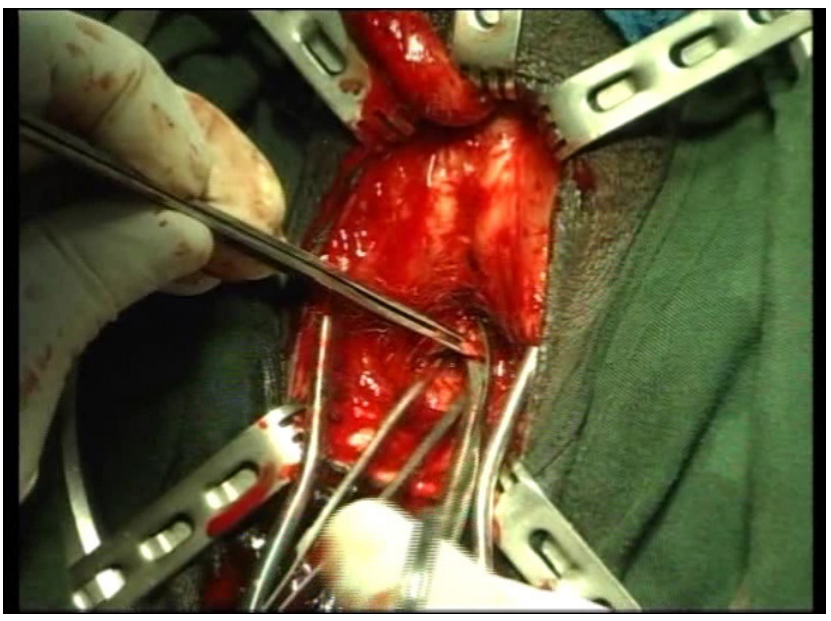

Figure 5. Excision of fibrosed spongiosum being carried out. Complete excision of fibrosed spongiosum is key to success in EPA EPA: Excision and primary anastomosis 


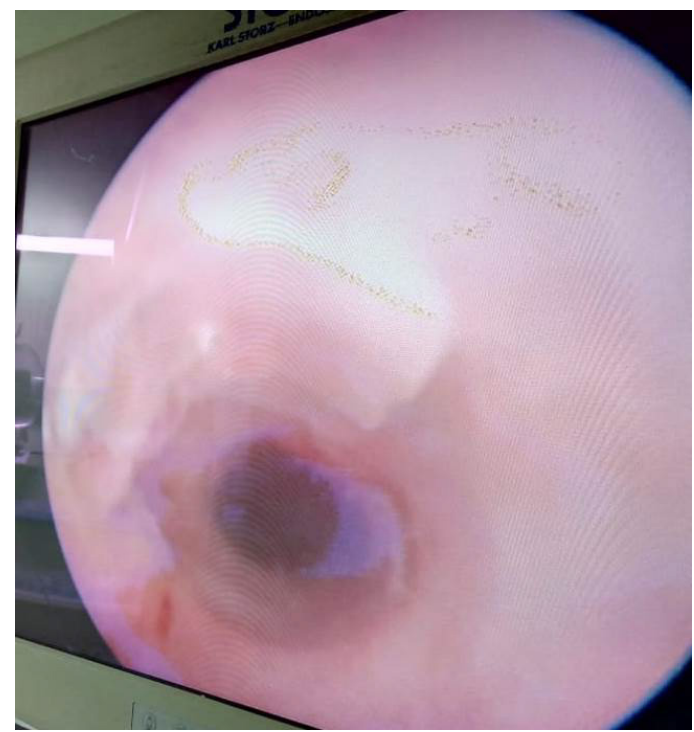

Figure 6. Check cystoscopy in a patient of EPA showing patent urethra EPA: Excision and primary anastomosis

posterior urethral stricture. All these five patients had satisfactory results in the postoperative period. Since the early 1990s, buccal mucosal graft has been the most used graft material for substitution urethroplasty. The overall success rates of onlay graft urethroplasty are about $90 \%$ when used in the bulbar urethra (20).

\section{Conclusion}

Pediatric urethral strictures have a diverse etiology of which trauma is the most common. The procedure to address a stricture should be tailored to the individual urethral anatomy, stricture length and the surgeon's experience. For smaller and partially obstructing strictures, DVIU or DU can be tried but these seem to be less effective than EPA, with high rates of secondary procedures. However, if not accompanied by complete excision of the fibrosed spongiosum, EPA may have recurrences. For longer strictures, substitution and urethroplasties are viable alternatives.

\section{Ethics}

Ethics Committee Approval: This prospective study extended from November 2012 to November 2020 after ethical clearance by institutional ethical committee.

Informed Consent: Informed consent was obtained from the legal guardians of the patients.

Peer-review: Externally peer-reviewed.

\section{Authorship Contributions}

Design: M.S., Data Collection or Processing: M.F.H., Analysis or Interpretation: V.J., N.M., Writing: M.F.H.

Conflict of Interest: No conflict of interest was declared by the authors.

Financial Disclosure: The authors declared that this study received no financial support.

\section{References}

1. Docimo SG, Canning D, Khoury A, Salle IL, editors. The Kelalis-King--Belman Textbook of Clinical Pediatric Urology. Routledge, CRC Press, 2018

2. Chapple CR. Urethral injury. BJU Int 2000; 86:318-26.

3. Basiri A, Shadpour P, Moradi MR, Ahmadinia H, Madaen K. Symphysiotomy: a viable approach for delayed management of posterior urethral injuries in children. J Urol 2002; 168:2166-9.

4. Sugimoto $M$, Kakehi Y, Yamashita M, Matsuki T, Inui M, Taketa $\mathrm{S}$. Ten cases of congenital urethral stricture in childhood with enuresis. International journal of urology. 2005 Jun;12(6):55862.

5. Alwaal A, Blaschko SD, McAninch JW, Breyer BN. Epidemiology of urethral strictures. Transl Androl Urol 2014; 3:209-13.

6. Ranjan $\mathrm{P}$, Ansari MS, Singh M, Chipde SS, Singh R, Kapoor R. Post-traumatic urethral strictures in children: What have we learned over the years? J Pediatr Urol 2012; 8:234-9.

7. Herle K, Jehangir S, Thomas RJ. Stricture urethra in children: an indian perspective. I Indian Assoc Pediatr Surg 2018; 23:192-7.

8. Pichler R, Fritsch H, Skradski V, et al. Diagnosis and management of pediatric urethral injuries. Urol Int 2012; 89:136-42.

9. Lal R, BhatnagarV, Mitra DK. Urethral strictures after fulguration of posterior urethral valves. J Pediatr Surg 1998; 33:518-9.

10. Babu R, Kumar R. Early outcome following diathermy versus cold knife ablation of posterior urethral valves. J Pediatr Urol 2013; 9:7-10

11. Gobbi D, Leon FF, Gnech M, et al. Management of congenital urethral strictures in infants. Case series. Urol / 2019; 16:67-71.

12. Banks FC, Griffin S), Steinbrecher HA, Malone PS. A etiology and treatment of symptomatic idiopathic urethral strictures in children. J Pediatr Urol 2009; 5:215-8

13. Heyns CF, Van Der Merwe J, Basson J, Van Der Merwe A. Etiology of male urethral strictures-Evaluation of temporal changes at a single center, and review of the literature. African J Urol 2012; 18:4-9.

14. Avanoglu A, Ulman I, Herek Ö, Özok G, Gökdemir A. Posterior urethral injuries in children. Br J Urol 1996; 77:597-600.

15. Holland A), Cohen RC, McKertich KM, Cass DT. Urethral trauma in children. Pediatr Surg Int 2001; 17:58-61.

16. Fahmy M. Congenital Urethral Stricture. In Congenital Anomalies of the Penis. New York, Springer, 2017. p. 215-20.

17. Singh A, Panda SS, Bajpai M, Jana M, Baidya DK. Our experience, technique and long-term outcomes in the management of posterior urethral strictures. I Pediatr Urol 2014; 10:40-4. 
18. Bayne DB, Gaither TW, Awad MA, Murphy GP, Osterberg EC, Breyer BN. Guidelines of guidelines: a review of urethral stricture evaluation, management, and follow-up. Transl Androl Urol 2017; 6:288-94

19. Launonen E, Sairanen I, Ruutu M, Taskinen S. Role of visual internal urethrotomy in pediatric urethral strictures. I Pediatr Urol 2014; 10:545-9.

20. Gallegos, MA, Santucci RA. Advances in urethral stricture management. F1000Res 2016; 5:2913.
21. Ranjan $\mathrm{P}$, Ansari MS, Singh $M$, Chipde SS, Singh R, Kapoor R. Post-traumatic urethral strictures in children: What have we learned over the years? J Pediatr Urol 2012; 8:234-9.

22. Faris SF, Myers JB, Voelzke BB, et al. Assessment of the male urethral reconstruction learning curve. Urology 2016; 89:137-43.

23. Al-Qudah HS, Santucci RA. Extended complications of urethroplasty. Intl Braz I Urol 2005; 31:315-25. 